\title{
Decline of arterial cerebral infarction among young women: the Bergen Stroke Study
}

\author{
This article was published in the following Dove Press journal: \\ Vascular Health and Risk Management \\ I5 February 201I \\ Number of times this article has been viewed
}

\author{
Halvor Naess' \\ Annette Fromm' \\ Ole Erik Iversen ${ }^{2}$ \\ Lars Thomassen' \\ Ulrike Waje-Andreassen' \\ 'Department of Neurology, \\ ${ }^{2}$ Department of Gynecology, \\ Haukeland University Hospital, \\ University of Bergen, Norway
}

Correspondence: Halvor Naess Deparment of Neurology, Haukeland University Hospital, Bergen, Norway Tel +4755975000

Fax +4755975I65

Email haln@haukeland.no
Objective: To assess the frequency of females and males aged $\leq 30$ years with cerebral infarction in two different time periods.

Methods: All patients aged $\leq 30$ years with arterial cerebral infarction in 1988-1997 and 2006-2010 admitted to Haukeland University Hospital in Bergen, Norway, were included. Risk factors and etiology were assessed.

Results: Between 1988 and 1997, 16 females and 7 males had cerebral infarction, whereas 0 females and 13 males had cerebral infarction in 2006-2010 $(P=0.0001)$. The incidence of cerebral infarction in females was significantly lower between 2006 and 2010 than between 1988 and $1997(P=0.007)$.

Conclusion: Our findings suggest that the frequency of cerebral infarction among young females has dropped significantly during recent years.

Keywords: cerebral infarction, Hordaland County, young females, males

\section{Introduction}

Previous studies have usually shown that cerebral infarction is more frequent among males than among females aged under 45 years. ${ }^{1,2}$ However, females outnumber males in most studies, including patients aged under 30 years. ${ }^{3}$ A large study from Denmark showed significantly more females aged under 35 years than males with cerebral infarction. ${ }^{4}$ A large recent study from Finland reported more females with cerebral infarction among patients aged under 30 years. ${ }^{2}$ Smaller studies have also reported a predominance of females with cerebral infarction aged under 30 years..$^{5-8}$

Consistent with these studies, we published a population-based study including young patients with cerebral infarction between 1988 and 1997 in Hordaland, Norway. The percentage of cerebral infarction among females aged under 30 years was $70 \%$ and $30 \%$ among males. ${ }^{9}$ However, the predominance of young females with cerebral infarction may be changing. Here we report a significant decline in cerebral infarction among young females aged $\leq 30$ years in recent years in Hordaland, Norway.

\section{Methods}

Cerebral infarction was defined in accordance with the Baltimore-Washington Cooperative Young Stroke Study criteria comprising neurological deficits lasting more than 24 hours because of ischemic lesions or transient ischemic attacks where computed tomography (CT) or magnetic resonance imaging (MRI) showed infarctions related to the clinical findings. ${ }^{10}$ The Department of Neurology at Haukeland University Hospital is responsible for all stroke patients younger than 60 years of age in Hordaland County. Only patients with arterial infarctions were included. 


\section{Patients 1988-1997}

This patient group includes the cohort of people aged $>15$ years and $\leq 30$ years living in Hordaland County with their first ever cerebral infarction from 1988 to 1997. All patients had CT or MRI. The patients were found retrospectively as described previously. ${ }^{9}$

\section{Patients 2006-2010}

All consecutive patients with acute cerebral infarction (the index stroke) admitted to the Stroke Unit, Department of Neurology, Haukeland University Hospital, between February 2006 and March 2010 were prospectively registered in a database (the Bergen Stroke Study, which started in February 2006). The present study includes patients aged $>15$ years and $\leq 30$ years. All patients had CT or MRI including diffusion-weighted imaging (DWI).

\section{Etiology and risk factors}

The definitions of etiology and risk factors were similar in both periods. Etiology was determined by the TOAST (Trial of Org 10172 in Acute Stroke Treatment) classification. ${ }^{11}$ Hypertension was defined as treatment with antihypertensive drugs before stroke onset or introduction of antihypertensive treatment before discharge. The indication for hypertensive treatment may have undergone change over the years. Diabetes mellitus was considered present if it was diagnosed before stroke onset (patient on a glucose-lowering diet or medication) or during hospital stay (fasting blood glucose $>7.7 \mathrm{mmol} / \mathrm{L}$ ). Angina pectoris, myocardial infarction, and atrial fibrillation were considered present if diagnosed by a physician any time before stroke onset. Smoking was defined as smoking at least one cigarette per day. The presence of migraine was based on self-report for patients in the 1988-1997 period and by interview for patients in the 2006-2010 period.

\section{Statistics}

Chi-square test was used to compare the frequencies of females and males in the two time periods. Separate analyses were performed comparing the incidence of cerebral infarction among females and males living in Hordaland County in the two time periods. Stata 11 (StataCorp LP, College Station, Texas, USA) was used for analysis.

\section{Results}

A total of 23 patients aged $\leq 30$ years were admitted with cerebral infarction between 1988 and 1997: 16 (70\%) females and $7(30 \%)$ males. Mean age for the females was 24.8 years (median 26.4 years and range 19.0-29.8 years). Mean age for the males was 22.7 years (median 23.0 years and range
17.1-28.4 years). Between 2006 and 2010, 13 patients aged $\leq 30$ years were admitted with cerebral infarction: $0(0 \%)$ females and $13(100 \%)$ males (Table 1). Mean age for the males was 25.4 years (median 25.5 years and range 18.2-30.7 years). Thus, the percentages of females and males in the two time periods differed markedly $(P=0.0001)$. Including patients living in Hordaland County showed that the incidence of cerebral infarction was significantly lower between 2006 and 2010 compared with between 1988 and 1997 for females ( 0 versus $3.3 / 100,000$ per year, $P=0.007)$. Eight males with cerebral infarction between 2006 and 2010 lived in Hordaland County. There was no difference as to incidence of cerebral infarction among males living in Hordaland County in the two time periods $(1.3 / 100,000$ per year between 1988 and 1997 versus 3.5/100,000 per year between 2006 and 2010, $P=0.12$ ). All patients from both time periods were born in Norway.

For comparison, 129 patients (54 [41.9\%] females) aged 31-45 years were admitted because of cerebral infarction between 1988 and 1997, and 64 patients (17 [26.6\%] females) were admitted between 2006 and $2010(P=0.04)$.

Table 2 shows characteristics of males and females with cerebral infarction between 1988 and 1997 and between 2006 and 2010. All females with cerebral infarction between 1988 and 1997 had CT, and cerebral infarction was disclosed among 10 (63\%). MRI was performed among 7 (44\%), and all scans showed cerebral infarction. Cerebral infarction was related to pregnancy or the postpartum period in $6(38 \%)$. Nine $(56 \%)$ females smoked, whereas $1(14.3 \%)$ male smoked. All males had CT and 5 (71.4\%) had MRI between 1988 and 1997. All males had CT and 12 (92.3\%) had DWI between 2006 and 2010 .

The main difference between males with cerebral infarction in 1988-1997 and 2006-2010 was more frequent determination of etiology in 2006-2010.

\section{Discussion}

The most important finding in the present study was that although females aged $\leq 30$ years dominated among patients with cerebral infarction between 1988 and 1997, no female aged $\leq 30$ years was hospitalized because of cerebral infarction between 2006 and 2010 in our hospital. Thus, our data show that there has recently been an important decline

Table I The numbers of males and females aged $\leq 30$ years with cerebral infarction in 1988-1997 and 2006-2010 (data are expressed as $\mathrm{n}(\%)$

\begin{tabular}{llllll}
\hline & \multicolumn{2}{l}{ 1988-1997 } & \multicolumn{2}{l}{ 2006-2010 } & $P$ \\
\hline Females & 16 & $(69.6)$ & 0 & $(0)$ & 0.0001 \\
Males & 7 & $(31.4)$ & 13 & $(100)$ & \\
\hline
\end{tabular}


Table 2 Characteristics of males and females aged $\leq 30$ years with cerebral infarction in 1988-1997 and 2006-2010

\begin{tabular}{|c|c|c|c|c|c|c|c|c|}
\hline & \multicolumn{2}{|c|}{$\begin{array}{l}\text { Females } \\
\text { |988-|997 }\end{array}$} & \multicolumn{2}{|c|}{$\begin{array}{l}\text { Females } \\
2006-2010\end{array}$} & \multicolumn{2}{|c|}{$\begin{array}{l}\text { Males } \\
\text { |988-|997 }\end{array}$} & \multicolumn{2}{|c|}{$\begin{array}{l}\text { Males } \\
2006-2010\end{array}$} \\
\hline & $\mathbf{n}$ & $\%$ & $\mathbf{n}$ & $\%$ & $\mathbf{n}$ & $\%$ & $\mathbf{n}$ & $\%$ \\
\hline \multicolumn{9}{|l|}{ Risk factors } \\
\hline Hypertension & 0 & 0 & 0 & 0 & 1 & 14.3 & 1 & 7.7 \\
\hline Diabetes mellitus & I & 6.3 & 0 & 0 & 0 & 0 & 0 & 0 \\
\hline Smoking & 9 & 56.3 & 0 & 0 & I & 14.3 & 3 & 27.3 \\
\hline Coronary heart & 0 & 0 & 0 & 0 & 0 & 0 & I & 7.7 \\
\hline \multicolumn{9}{|l|}{ disease } \\
\hline Atrial fibrillation & 0 & 0 & 0 & 0 & 0 & 0 & 0 & 0 \\
\hline Migraine & 5 & 31.3 & 0 & 0 & 2 & 28.6 & 2 & 20 \\
\hline Oral contraceptive & 7 & 43.8 & 0 & 0 & 0 & 0 & 0 & 0 \\
\hline \multicolumn{9}{|l|}{ Etiology } \\
\hline Atherosclerosis & 0 & 0 & 0 & 0 & 1 & 14.3 & 0 & 0 \\
\hline Cardiac embolism & I & 6.3 & 0 & 0 & 0 & 0 & 5 & 38.5 \\
\hline PFO & I & 6.3 & 0 & 0 & 0 & 0 & 4 & 36.4 \\
\hline Small vessel disease & 0 & 0 & 0 & 0 & I & 14.3 & I & 7.7 \\
\hline Dissection & I & 6.3 & 0 & 0 & 0 & 0 & 4 & 30.8 \\
\hline Pregnancy & 4 & 25 & 0 & 0 & 0 & 0 & 0 & 0 \\
\hline Postpartum & 2 & 12.5 & 0 & 0 & 0 & 0 & 0 & 0 \\
\hline Elevated homocystein & I & 6.3 & 0 & 0 & 0 & 0 & 0 & 0 \\
\hline Unknown & 0 & 0 & 0 & 0 & 4 & 57.1 & 3 & 23.1 \\
\hline Infarction on $\mathrm{CT}$ & 10 & 62.5 & 0 & 0 & 5 & 71.4 & 7 & 53.9 \\
\hline Infarction on MRI & 7 & 100 & 0 & 0 & 5 & 100 & 12 & 100 \\
\hline $\mathrm{mRS} 0$ & 3 & 18.8 & 0 & 0 & 0 & 0 & 0 & 0 \\
\hline mRS I & 6 & 37.5 & 0 & 0 & I & 14.3 & 3 & 23.1 \\
\hline mRS 2 & 6 & 37.5 & 0 & 0 & 4 & 57.1 & 5 & 38.5 \\
\hline mRS 3 & I & 6.3 & 0 & 0 & 2 & 28.6 & 3 & 23.1 \\
\hline $\mathrm{mRS} 4$ & 0 & 0 & 0 & 0 & 0 & 0 & I & 7.7 \\
\hline mRS 5 & 0 & 0 & 0 & 0 & 0 & 0 & 0 & 0 \\
\hline mRS 6 & 0 & 0 & 0 & 0 & 0 & 0 & I & 7.7 \\
\hline
\end{tabular}

Abbreviations: CT, computed tomography; PFO, patent foramen ovale; MRI, magnetic resonance imaging; mRS, modified Rankin score.

in the frequency of cerebral infarction among young females. The frequency of males with cerebral infarction was higher between 2006 and 2010 than between 1988 and 1997, but this difference was not statistically significant. There has been no change in the policy of admittance of cerebral infarction to the hospital in the study periods.

Most previous studies have reported a predominance of females with cerebral infarction in the age group $<30-35$ years. $^{2-9}$ However, most studies included patients before 2000. There are several possible causes for the reduced frequency of cerebral infarction among young females. Epidemiologic studies have shown that oral contraceptives (OCPs) are associated with cerebral infarction. ${ }^{12,13}$ This pertains especially to females with risk factors such as hypertension, diabetes mellitus, smoking, thrombophilic disorders, and migraine ${ }^{13-15}$ Low-dose OCPs may have contributed to the decline of cerebral infarction among young females. ${ }^{16-18}$

We found that cerebral infarction was associated with pregnancy and the postpartum period among $6(38 \%)$ females between 1988 and 1997. Although there has been no decline in total births between the two time periods in Hordaland
County, there has been a $20 \%$ decline of births among females aged $\leq 30$ years between the two time periods. ${ }^{19}$ This may partly explain the decline in cerebral infarction among females. Better control of pregnancy and birth may also have contributed to a lower risk of cerebral infarction.

Cerebral infarction is associated with smoking among young adults. ${ }^{20}$ The frequency of daily smoking among young adults in Norway has declined from about 30\% between 1988 and 1997 to less than $20 \%$ since 2006 , with few differences between the sexes. ${ }^{21}$ This may have contributed to a decline in cerebral infarction among young females, although there does not seem to be a corresponding decline among males. Furthermore, recent studies suggest that there has been a general decline in frequency of cerebral infarction irrespective of age. ${ }^{22}$ Possible causes include better control of traditional risk factors. ${ }^{23}$

The most important change in investigation of stroke patients in our department has been the introduction of DWI in 2000 . More than $80 \%$ of our patients undergo DWI. Frequent use of DWI improves the precision of diagnosis. It is possible that studies before the introduction of DWI were hampered by frequent misdiagnosis of cerebral infarction. 
Some venous infarctions may have been misdiagnosed as arterial infarctions. This may especially pertain to females in pregnancy and the postpartum period and therefore partly explain the decline in females diagnosed with arterial cerebral infarction. Long-lasting migraine aura is sometimes mistaken for cerebral infarction, and migraine is more frequent among females than among males. This pitfall may pertain to some patients recruited in the 1988-1997 period. The diagnostic work-up, including cardiac investigations and sonography of neck vessels, was more thorough in the 2006-2010 period.

One of the strengths of the present study is that it compares patients admitted to the same hospital, which alone covers a population of approximately 500,000 people, in two different time periods. However, there are a few limitations. The patients included in the 1988-1997 period were included retrospectively. Furthermore, we have no accurate data as to change in risk factor profile between the two time periods in the general population except for smoking. Therefore, we can only speculate as to the cause of decline in the frequency of cerebral infarction among young females. Another limitation is the low number of patients included in the study. There was a trend toward a higher incidence of cerebral infarction among males in the time period between 2006 and 2010. A longer study period is needed to investigate whether this increase is true.

\section{Conclusion}

Our findings suggest that the frequency of cerebral infarction among young females has dropped significantly during recent years in Hordaland, Norway.

\section{Disclosure}

The authors report no conflicts of interest in this work.

\section{References}

1. Kristensen B, Malm J, Carlberg B, et al. Epidemiology and etiology of ischemic stroke in young adults aged 18 to 44 years in northern Sweden. Stroke. 1997;28(9):1702-1709.

2. Putaala J, Metso AJ, Metso TM, et al. Analysis of 1008 consecutive patients aged 15 to 49 with first-ever ischemic stroke: the Helsinki young stroke registry. Stroke. 2009;40(4):1195-1203.

3. Bogousslavsky J, Pierre P. Ischemic stroke in patients under age 45. Neurol Clin. 1992;10(1):113-124.

Vascular Health and Risk Management

\section{Publish your work in this journal}

Vascular Health and Risk Management is an international, peer-reviewed journal of therapeutics and risk management, focusing on concise rapid reporting of clinical studies on the processes involved in the maintenance of vascular health; the monitoring, prevention and treatment of vascular disease and its sequelae; and the involvement of metabolic
4. Lidegaard O, Soe M, Andersen MV. Cerebral thromboembolism among young women and men in Denmark 1977-1982. Stroke. 1986;17(4): 670-675.

5. Adams HP Jr, Kappelle LJ, Biller J, et al. Ischemic stroke in young adults. Experience in 329 patients enrolled in the Iowa Registry of stroke in young adults. Arch Neurol. 1995;52(5):491-495.

6. Barinagarrementeria F, Figueroa T, Huebe J, Cantu C. Cerebral infarction in people under 40 years. Cerebrovasc Dis. 1996;6:75-79.

7. Rasura M, Spalloni A, Ferrari M, et al. A case series of young stroke in Rome. Eur J Neurol. 2006;13(2):146-152.

8. Carolei A, Marini C, Ferranti E, et al. A prospective study of cerebral ischemia in the young. Analysis of pathogenic determinants. The National Research Council Study Group. Stroke. 1993;24(3): 362-367.

9. Naess H, Nyland HI, Thomassen L, et al. Incidence and short-term outcome of cerebral infarction in young adults in western Norway. Stroke. 2002;33(8):2105-2108.

10. Johnson CJ, Kittner SJ, McCarter RJ, et al. Interrater reliability of an etiologic classification of ischemic stroke. Stroke. 1995;26(1): 46-51.

11. Adams HP Jr, Bendixen BH, Kappelle LJ, et al. Classification of subtype of acute ischemic stroke. Definitions for use in a multicenter clinical trial. TOAST. Trial of Org 10172 in Acute Stroke Treatment. Stroke. 1993;24(1):35-41.

12. Kemmeren JM, Tanis BC, van den Bosch MA, et al. Risk of Arterial Thrombosis in Relation to Oral Contraceptives (RATIO) study: oral contraceptives and the risk of ischemic stroke. Stroke. 2002;33(5): 1202-1208.

13. Lidegaard O, Kreiner S. Contraceptives and cerebral thrombosis: a five-year national case-control study. Contraception. 2002;65(3): 197-205.

14. Chang CL, Donaghy M, Poulter N. Migraine and stroke in young women: case-control study. The World Health Organization Collaborative Study of Cardiovascular Disease and Steroid Hormone Contraception. BMJ. 1999;318(7175):13-18.

15. Schwartz SM, Petitti DB, Siscovick DS, et al. Stroke and use of low-dose oral contraceptives in young women: a pooled analysis of two US studies. Stroke. 1998;29(11):2277-2284.

16. Chan WS, Ray J, Wai EK, et al. Risk of stroke in women exposed to low-dose oral contraceptives: a critical evaluation of the evidence. Arch Intern Med. 2004;164(7):741-747.

17. Petitti DB, Sidney S, Bernstein A, et al. Stroke in users of low-dose oral contraceptives. N Engl J Med. 1996;335(1):8-15.

18. Schwartz SM, Siscovick DS, Longstreth WT Jr, et al. Use of low-dose oral contraceptives and stroke in young women. Ann Intern Med. 1997; 127(8 Pt 1):596-603.

19. Statistics Norway. Population. http://www.ssb.no/english/subjects/02/ befolkning_en. Accessed January 28, 2011.

20. Naess H, Nyland HI, Thomassen L, et al. Etiology of and risk factors for cerebral infarction in young adults in western Norway: a population-based case-control study. Eur J Neurol. 2004;11(1):25-30.

21. Statistics Noway. Smoking and using snuff in Norway, 2009. http://www. ssb.no/english/subjects/03/01/royk_en. Accessed January 28, 2011.

22. Sivenius J, Tuomilehto J, Immonen-Raiha P, et al. Continuous 15 -year decrease in incidence and mortality of stroke in Finland: the FINSTROKE study. Stroke. 2004;35(2):420-425.

23. Ellekjaer H, Selmer R. [Stroke: similar incidence, better prognosis]. Tidsskr Nor Laegeforen. 2007;127(6):740-743.

\section{Dovepress}

disorders, particularly diabetes. This journal is indexed on PubMed Central and MedLine. The manuscript management system is completely online and includes a very quick and fair peer-review system, which is all easy to use. Visit http://www.dovepress.com/testimonials.php to read real quotes from published authors. 